\title{
Documentação e Divulgação da Agricultura no Brasil
}

\author{
José A. VIEIRA \\ (Diretor do Serviço de Informação Agrícola)
}

\begin{abstract}
A divulgação dos assuntos referentes à economia agrária do Brasil vem progredindo, nos últimos anos, a par do desenvolvimento geral do próprio Ministério da Agricultura.

Instalado em 1940, o Serviço de Informação Agrícola tem evoluido anımadoramente, embora, por falta de maiores recursos, ainda não conseguisse levar às populações do interior, em extensão e profundidade, os beneticios da difusão dos ensinamentos, conselhos e orientação dos técnicos e das autoridades. Mesmo assim, a obra do S.I.A. é bastante apreciada por quantos a conhecem ou dela se têm valido. Algumas Secretarias de Agricuítura Estaduais possuem, também, excelentes serviços de divulgação ou publicidade agricola, destacando-se as de São Paulo, Rio Grande do Sul, Minas Gerais, Paraná e Pernambuco. Contudo, tais serviços são de âmbito restrito e não reunem o conjunto de atribuições e modalidades como as que desenvolve o serviço de Informação Agrícola, visando a todo o território nacional.

Atualmente, conta o S.I.A. com uma Biblioteca e seis seções, a saber: Documentação, Publicações, Consultas e Informações, Extensão Agrícola, Divulgaçäo e Administrativa.
\end{abstract}

\section{DOCUMENTAÇÃO E BIBLIOTECA}

A sua Biblioteca, que funciona na Biblioteca Central do Ministério da Agricultura, possui cêrca de 28.000 volumes, abrangendo trabalhos os mais valiosos e diversos, de interêsse para especialistas, estudiosos e produtores, que podem acompanhar os progressos técnicos e científicos da agricultura mundial através das referências contidas nas "Notícias Bibliográficas", mensalmente editadas.

A seção de Documentação, depois do incêndio ocorrido em março de 1953, acha-se em fase de restauração, realizando trabalhos próprios e solicitando, das organizações agrícolas, material disponível, principalmente documentos e fotografias. Como documentação da vida rural, realiza dois planos importantes: o do Calendário Agrícola do Brasil (já foram publicados os reterentes aos Estados de São Paulo, Paraná e Distrito Federal, en. contrando-se em impressão o de Minas Gerais); e a série de monografias sôbre aspectos regionais característicos das atividades ruralistas, já tendo edi- 
tacio sete trabalhos dêsse gênero, por autores consagrados nas respectivas especialīdades. Elabora, ainda, o Relatório Anual do Ministério da Agricultura, com os elementos fornecidos pelos seus diversos órgãos.

\section{LIVROS, FOLHETOS E PERIÓdICOS}

Quanto a Publicações, o S. I. A. distribui cêrca de quinhentos mil exemplares anualmente, pelo preço de custo ou gratuitamente, para entidades interessadas. São folhetos e livros, de natureza técnica, destinados, sobretudo, a orientar os lavradores e criadores nas suas tarefas de produção.

Merece destaque especial a grande obra do "Dicionário das Plantas Uteis do Brasil", com três volumes publicados. A Seção de Publicações compreende os setores de impressão (Multilith), posto de venda e expedição. A maioria dos trabalhos é, porém, impressa em oficinas de outras entidades publicas ou particulares, neste caso, mediante concorrência pública. O jornal mensal "Intormação Agrícola", com 10 mil exemplares de tiragem, é remetido as associaçôes rurais, prefeituras municipais, autoridades e outros interessados.

A seção de Consultas e Informações atende pessoalmente, por telefone ou por carta, a mais de cinco mil interessados, por ano. Um de seus trabalhos ma1s úteis é o que se refere à disseminação de "comunicados técni$\cos ^{\prime \prime}$, para os jornais do interior, revistas especializadas e págínas agrícolas ans grandes jornais diários das Capitais. Elevam-se a mais de cento e trinta mil páginas mimeografadas os "comunicados" anualmente distribuidos.

\section{EXTENSÃO AGRÍCOLA}

Ėm 1954, com o novo regimento do S.I.A., foi criada a Seção de Extensao Agrícola, para reunir atividades típicas, como "semanas ruralistas", cursos de educação rural, missões rurais, cursos de economia domēstica e indústrias rurais caseiras, bem assim a campanha dos clubes agrícolas escolares. Já no ano passado, foram realizadas treze semanas ruralistas, nas diversas regiões do país, com a colaboração das autoridades estaduais, municipars e eclesiásticas, além dos técnicos do Ministério sediados no interior. Nia1s de trinta mil pessoas se beneficiaram com êsses certames, através de palestras, demonstrações práticas e exibições cinematográficas.

A campanha dos Clubes Ágrícclas, mantida há vários anos, está sendo melhor estudada para a adoção de rumos mais objetivos, em consequência do levantamento da situação dessas pequenas organizações, espalhadas pelos diterentes pontos do território nacional. $\mathrm{O}$ que se pretende é a instalação de, pelo menos, um clube agrícola modêlo em cada uma unidade da Federação e também o preparo de dirigentes para essas organizações, de forma a permitır o seu desenvolvimento e manutenção independentes da ajuda governamental, depois de um ou dois anos dessa assistência.

\section{DIVULGAÇÃo}

A obra de divulgação para as massas é feita através dos setores de Imprensa, Rádio e Cinema, num trabalho de vulto, que tem merecido satisfatória aceitação. Diariamente o S.I.A., através do Setor de Imprensa, for- 
nece noticiario aos jornais, agências telegráficas e emissôras sôbre as principa1s atıvidades do Ministério, notadamente os atos e resoluções do Titular da P'asta. No ano passado, além de milhares de cópias totográficas, foram distribuidas cërca de duas mil e oitocentas notícias diversas, tendo sido enviadas para mais de quatrocentos jornais do interior, seleções quinzenais daquele notıciárı, que alimenta e anima várias campanhas de interêsse da economia nacional.

U Setor de Rádiodifusão Rural prepara, diàriamente, dois informativos de cinco minutos para quatro emissôras cariocas. Aos domingos, das oito as rove, transmite o programa Terra Brasileira, em colaboração com a Rádio Mınıstério da Educação. E ainda remete, para duzentas e cinco emissôras do interior, semanalınente, um programa de quinze minutos. Foram tomadas diversas providências relacionadas com a guarda e instalação de aparelhagem destinada ao funcionamento da Rádio Rural. Possui, o Serviço, dois exceientes transmissores de ondas curtas; estúdios, com ar condicionado, no edifício-sede do Ministéric; terreno em Benfica, e dispõe, também, da concessão dos canais. Em face de obstáculos à construção do pavilhão, para abrigo dos transmissores e início de funcionamento, o Ministério da Agricultura solicitou ao da Viação providências complementares para assegurar a respectiva İicença, já há tempos outorgada. Com a cooperação das entidades agrícolas, a radiodifusão rural tende a desenvolver-se no Brasil, de modo a prestar maiores serviços aos lavradores e criadores.

Én matéria cie Cinema Agrícola, o S.I.A. chegou a produzir cêrca de trezentos tılmes, a maioria de propaganda e ilustração das atividades rurais. Intelizmente, o lahoratório de cinematografia e a filmoteca foram destruidos, quase totalmente, pelo incèndio ocorrido. Em virtude do alto custo da aparelhagein necessária, é demorada a reinstalação dêsse serviço, que, entretanto, está sendo levado a efeito, dentro das possibilidades atuais. A orientação firmada visa a preparar a implantação de um cinema educativo para as populaçoes ruraıs, quer em $35 \mathrm{~mm}$., quer em $16 \mathrm{~mm}$., sendo que êste está destinado a desempenhar papel relevante nos trabalhos de extensão agrícola e divulgaçao técnica. Nesse sentido, numerosas são as solicitações das entidades púbīicas @ particulares dedicadas a programas de educação extensiva no meio rural.

\section{RELAÇÕES PÚBLICAS}

Considerando, por fim, a conveniência de coordenar e disciplinar, num único Setor, as atividades do S. I. A. caracterizadamente de Relações Públicas, obtendo-se maior eficiência à sua atuação e do Ministério, no partıcular, o minıstro Costa Pôrto assinou Portaria (n. ${ }^{\circ}$ 144, de 9-11-55) criando o setor de Relações Públicas. Além das tarefas específicas à atribuição, êste Setor articula-se com os demais órgãos da administração púbïica, máxime os do próprio Ministério, promovendo as medidas necessárias a uma atuação unitorme nèsse campo de atividade, não só nesta Capital, mas também nos Estados e Territórios. 


\section{RECURSOS E PERSPECTIVAS}

São esses os principais trabalhos que o Serviço de Informação Agrícola vem desenvolvendo em favor da agricultura nacional. Para essa obra dispôs, no ano passado, de recursos da ordem de vinte milhões de cruzeiros, conpreendendo dez milhões para Serviços e Encargos, seis milhões para Material e quatro milhoes para Pessoal, integrado por quarenta e cinco titulados e noventa extranumerários mensalistas. Prestam, ainda, serviços, em regime especial, trinta colaboradores.

Um índice da atividade do S.I.A. é revelado pela movimentação de ma1s de quarenta mil fichas anuais, através da Seção Administrativa, que mantem o protocolo do Serviço e trata de tudo quanto se relaciona com pessoal, material, orçamento e comunicações.

Camınha, assim, o Serviço de Informação Agrícola para se transformar não só no órgão típico de relações públicas do Ministério da Agricultura, mas também num grande centro de informações da economia rural brasileira, procurando, ainda, estabelecer uma verdadeira rêde nacional de divulgação agricola, de modo a mobilizar a opinião pública do país em favor do maior desenvolvimento e racionalização das suas atividades agro-pecuárias.

A documentação acompanha o documento desde $\circ$ instante em que êle surge da pena do autor até o momento em que impressiona o cérebro do leitor. Ela é ativa ou passiva, receptiva ou dativa; está em tôda parte onde se fale (Universidade), onde se leia (Biblioteca), onde se discuta (Sociedade), onde se colecione (Museu), onde se pesquise (Laboratório), onde se administre (Administração), onde se trabalhe (Oficina).

$$
\text { PAUL OTrET - Separata da "R.S.P.", } 1947 .
$$

